\title{
Bupropion Reduces Methamphetamine-Induced Subjective Effects and Cue-Induced Craving
}

\author{
Thomas F Newton*,', John D Roache², Richard De La Garza II', Timothy Fong', Christopher L Wallace ${ }^{2}$, \\ Shou-Hua Li ${ }^{3}$, Ahmed Elkashef ${ }^{3}$, Nora Chiang ${ }^{3}$ and Roberta Kahn ${ }^{3}$ \\ 'Department of Psychiatry and Biobehavioral Sciences, David Geffen School of Medicine at The University of California at Los Angeles, Los \\ Angeles, CA, USA; ${ }^{2}$ Department of Psychiatry, University Clinical Psychopharmacology Laboratory, University of Texas Health Science Center at \\ San Antonio, San Antonio, TX, USA; ${ }^{3}$ Division of Pharmacotherapies and Medical Consequences of Drug Abuse, National Institute on Drug Abuse, \\ Bethesda, MD, USA
}

\begin{abstract}
Bupropion is an antidepressant with stimulant properties, which inhibits the reuptake of dopamine (DA) and norepinepherine, and is purported to enhance DA neurotransmission. Bupropion is considered an appealing candidate medication for the treatment of methamphetamine dependence. The current laboratory study was set forth to assess the impact of bupropion treatment on the subjective effects produced by methamphetamine in the laboratory. We also assessed the effects of bupropion treatment on craving elicited by exposure to videotaped methamphetamine cues. A total of 26 participants were enrolled and 20 completed the entire study ( $n=10$ placebo and $n=10$ bupropion, parallel groups design). Bupropion treatment was associated with reduced ratings of 'any drug effect' $(p<0.02)$, and 'high' $(p<0.02)$ following methamphetamine administration. There was also a significant bupropion-by-cue exposure interaction on General Craving Scale total score $(p<0.002)$, and on the Behavioral Intention subscale $(p<0.00 \mathrm{I})$. Overall, the data reveal that bupropion reduced acute methamphetamine-induced subjective effects and reduced cue-induced craving. Importantly, these data provide a rationale for the evaluation of bupropion in the treatment of methamphetamine dependence. Neuropsychopharmacology (2006) 3 I, I537- 1544. doi: I0. I038/sj.npp. I 300979; published online 23 November 2005
\end{abstract}

Keywords: human; dopamine; norepinepherine; addiction; dependence

\section{INTRODUCTION}

Methamphetamine dependence directly or indirectly affects millions of Americans, and despite the efficacy of current treatments for some patients, relapse remains a significant problem (Huber et al, 1997; Rawson et al, 1999, 2004; Shoptaw et al, 1994). These studies, along with many others, underscore the challenge inherent in providing effective treatment to methamphetamine users.

A number of factors are thought to contribute to relapse, including drug availability and exposure to drug cues. Drug cues ('triggers') include people, places, and things associated with drug use. This has been studied more fully in opiate and cocaine dependence, although similar considera-

\footnotetext{
*Correspondence: Dr TF Newton, Department of Psychiatry and Biobehavioral Sciences, David Geffen School of Medicine at UCLA, 740 Westwood Blvd., Semel Institute for Neuroscience and Human Behavior, Suite A7-372, Los Angeles, CA 90024, USA, Tel: + I 310 267 0159, Fax: + I 310794995 I, E-mail: tnewton@mednet.ucla.edu Received 3 June 2005; revised 21 September 2005; accepted 20 October 2005

Online publication: 20 October 2005 at http://www.acnp.org/citations/ Npp 10200505036 //default.pdf
}

tions are likely to apply to dependence on methamphetamine (Ehrman et al, 1992; O'Brien et al, 1976).

There have been sustained and partly successful efforts to develop medication treatments for drug abuse disorders (de Lima et al, 2002; Garbutt et al, 1999; Mattick et al, 2002; Sofuoglu and Kosten, 2005), although fewer medications have been studied in randomized clinical trials for the treatment of methamphetamine dependence (Galloway et al, 1994, 1996; Huber et al, 2000).

Bupropion is an attractive candidate medication for the treatment of methamphetamine dependence for several reasons. Bupropion is an antidepressant with stimulant properties (Stahl et al, 2004) that is effective for the treatment of nicotine dependence (Richmond and Zwar, 2003). In a clinical trial of bupropion for cocaine dependence (Margolin et al, 1995), an exploratory analysis suggested that patients with greater levels of depression may have benefited the most. Clinically, acute abstinence from methamphetamine in chronic users is associated with depression and impaired concentration (Newton et al, 2004). These symptoms may be due to methamphetamineinduced neuroadaptations in presynaptic DA neurons manifest as reduced striatal DA availability (McCann et al, 1998; Sekine et al, 2003; Volkow et al, 2001; Wilson et al, 
1996). Bupropion inhibits the reuptake of DA and enhances residual DA neurotransmission, effects that may ameliorate methamphetamine abstinence symptoms. The current laboratory study was designed to assess the impact of bupropion treatment on the subjective effects produced by methamphetamine and to assess the effects of bupropion treatment on craving elicited by exposure to methamphetamine cues.

\section{MATERIALS AND METHODS}

\section{Subjects}

In total, 26 participants were enrolled and 20 completed the entire study ( $n=10$ placebo and $n=10$ bupropion, parallel groups design). Participants were recruited through advertisements and were paid for their participation. All met DSM-IV-TR criteria for methamphetamine abuse or dependence and were not seeking treatment at the time of study entry. Other inclusion criteria included being between 18 and 45 years of age, a history of using methamphetamine by the smoked or intravenous (i.v.) route, twice-weekly use of methamphetamine in 4 of the 6 weeks prior to screening, and normal laboratory assessment and vital signs. Exclusion criteria included a history of seizure disorder, head trauma, dependence on other drugs aside from nicotine, prior adverse reaction to methamphetamine, or the presence of any other axis I psychiatric disorder. Serious medical conditions such as heart disease, AIDS, asthma, Parkinson's disease, and other serious medical conditions were also exclusionary. Concomitant use of psychotropic medications or medications interacting with bupropion was not allowed. This study was approved by the institutional review boards at both UCLA and the University of Texas Health Sciences Center at San Antonio (UTHSCSA), and all participants gave informed consent after being fully informed about potential risks of participation.

\section{Study Design}

The study was conducted using a double-blind design at UCLA and UTHSCSA. Following admission to the clinical research center (CRC), subjects received a baseline series of i.v. doses of methamphetamine $(0,15$, and $30 \mathrm{mg})$. Subjects received a second identical series of methamphetamine doses 6 days after initiation of twice-daily oral placebo or bupropion treatment. The order of the methamphetamine 0 and $15 \mathrm{mg}$ administration sessions was randomly assigned, although the $30 \mathrm{mg}$ methamphetamine dose always followed the lower doses (see Study Scheme: Table 1). Thus, the investigators (but, not the participants) were not blinded to the $30 \mathrm{mg}$ methamphetamine dose. Assignment of placebo and bupropion was random, and stratified by site.

\section{Drugs}

Commercially available bupropion tablets (150 mg extended-release) were cut in half (due to the large size of the tablet) and encapsulated in gelatin capsules by research pharmacies at each site. The manufacturer provided documentation that these procedures did not affect
Table I Summary of i.v. Doses of Methamphetamine Administered at Baseline and 6 Days after Initiation of Twice-Daily Oral Placebo or Bupropion Treatment

\begin{tabular}{lccc}
\hline Study phase & Session & Study day & $\begin{array}{c}\text { Methamphetamine } \\
\text { challenge (mg) }\end{array}$ \\
\hline Baseline & 1 & 2 & 0 or 15 \\
Baseline & 2 & 3 & 0 or 15 \\
Baseline & 3 & 5 & 30 \\
Treatment & 4 & & 0 or 15 \\
Treatment & 5 & 18 & 0 or 15 \\
Treatment & 6 & 22 & 30 \\
\hline
\end{tabular}

bioavailability of the bupropion (personal communication to Dr John Roache). Placebo was prepared in a similar manner. A NIDA contractor provided sterile methamphetamine solution for human use and a saline solution of equal volume and appearance was used as the control. An IND was obtained from the FDA for the use of bupropion and methamphetamine in this study. Methamphetamine was administered over 2 min (between 0900 and 1100 hours on specified infusion days) using an i.v. pump.

\section{Subjective Measures}

Subjective effects data were collected using computerized visual analog rating scales (VAS), the Within Session Rating Scale (WSRS, a craving rating scale), the General Craving Scale (GCS)(Merikle, 1999), the Multiple Choice Questionnaire (MCQ), Brief Psychiatric Rating Scale (BPRS), Adjective Scales, and the Addiction Research Center Inventory (ARCI) (Haertzen, 1965, 1966).

VAS data were collected at $15 \mathrm{~min}$ before, and 3, 6, 10, 15, $30,45,60,90,120,180,240,300,360,420$, and $480 \mathrm{~min}$ following methamphetamine or placebo administration. For the VAS scales, subjects reported the degree to which they feel 'any drug effect', 'high', 'good effects', 'bad effects', 'like methamphetamine', 'desire for methamphetamine', 'depressed', 'anxious', 'stimulated', and 'likely to use' on a continuous scale digitized between 0 and 100. In addition, they were asked to answer the question: 'How much would you pay for this drug'?

Within the first several days of the study, participants rated craving (using the WSRS and the GCS) prior to and following exposure to a neutral cue video consisting of a nature scene. On subsequent days (twice prior to randomization and twice after randomization), participants rated craving prior to and following exposure to a cue video showing actors using drugs. Cueing procedures took place on days that participants could potentially receive $15 \mathrm{mg}$ methamphetamine in order to maintain the salience of the cues. The GCS consists of 59 questions rated on a scale of $1-5$, and yields data on several dimensions, including 'behavioral intention', 'physical symptoms', 'positive outcome', 'affect', 'cues affect', and several others.

Participants also completed the MCQ, in which participants complete a series of hypothetical choices between 
doses of methamphetamine and varying amounts of money. The crossover point indicated how much participants would pay for a dose of methamphetamine.

The BPRS is a psychiatrist-administered interview that was conducted $60 \mathrm{~min}$ after methamphetamine/saline infusion sessions. The BPRS evaluates the severity of subject's psychopathology, including anxiety, depression, and symptoms of schizophrenia. The BPRS total score ratings serve as indicators of psychiatric comorbidity in drugdependent subjects and as predictors of mental health services utilization.

Adjective Scales consisted rating of 22 adjectives on a scale of $0-4$, ranging from 'not at all' to 'extremely', and the ARCI consisted of 49 statements in a true/false format. The BPRS was administered $60 \mathrm{~min}$ following methamphetamine administration to detect possible behavioral toxicity (Overall and Gorham, 1962). The Adjective Scales and the ARCI were administered $15 \mathrm{~min}$ before and at $30 \mathrm{~min}$ after each infusion. The ARCI and Adjective Scale were included to assist interpretation, if needed.

\section{Data Analysis}

The primary outcome measures were changes in subjective ratings following administration of i.v. methamphetamine, as compared to placebo. A secondary outcome measure was change in self-reported craving following exposure to a cue video showing actors using drugs. Descriptive statistics for demographic data are presented for all subjects $(n=26)$. However, because of the need to balance the mixed repeated measures design, inferential analyses of the primary outcome data were possible only for the 20 completers. Subjective effects data were analyzed using SAS Proc Mixed (Release 8.2). Fixed effects of Bupropion dose (0 or $150 \mathrm{mg}$ ), Period (before $v s$ after initiation of bupropion/placebo treatment), and Methamphetamine dose $(0,15$, or $30 \mathrm{mg})$ were specified in a factorial design (with repeated measures on Period and Methamphetamine dose). In addition, we also examined the effects of Bupropion and Period on the maximum subjective effects reported following methamphetamine administration, using the baseline response immediately prior to dosing as a covariate. The covariance structure was specified as autoregressive and the empirical option was used to maximize validity of this assumption.

\section{RESULTS}

\section{Demographics and Drug Use}

A total of 26 participants were enrolled and 20 completed the entire study $(n=10$ placebo and $n=10$ bupropion, parallel groups design). Data are presented as a comparison of patients who dropped from the study $v s$ those who completed (Table 2), as well as a comparison of all patients who completed and were treated with either bupropion or placebo (Table 3). No significant differences were noted for these comparisons.

Of completers, the majority were non-Hispanic white $(55 \%)$, male $(65 \%)$, and had a mean age of $32.8 \pm 8.4$ years. The majority of completers met criteria for current methamphetamine dependence or current methamphetamine abuse. In addition to methamphetamine use, the
Table 2 Participant Demographics and Drug Use Data for Drops and Completers

\begin{tabular}{|c|c|c|c|c|}
\hline & $\begin{array}{l}\text { Drops } \\
(N=6)\end{array}$ & $\begin{array}{l}\text { Completers } \\
(N=20)\end{array}$ & $\begin{array}{l}\text { Total } \\
(N=26)\end{array}$ & \\
\hline \multicolumn{5}{|l|}{ Gender, N (\%) } \\
\hline Male & $4(67)$ & $13(65)$ & $17(65)$ & \\
\hline Female & $2(33)$ & $7(35)$ & $9(35)$ & \\
\hline \multicolumn{5}{|l|}{ Single major race, $N(\%)$} \\
\hline White, not Hispanic & $4(67)$ & II (55) & $26(58)$ & \\
\hline Hispanic or Latino & $2(33)$ & $6(30)$ & $8(31)$ & \\
\hline African American or Black & $0(0)$ & । (5) & । (4) & \\
\hline Other & $0(0)$ & $2(10)$ & $2(8)$ & \\
\hline \multicolumn{5}{|l|}{ Age (years) } \\
\hline \multirow[t]{3}{*}{ Mean $\pm S D$} & $29.7 \pm 6.6$ & $32.8 \pm 8.4$ & $32 \pm 8$ & \\
\hline & \multicolumn{2}{|c|}{ Drops } & \multicolumn{2}{|c|}{ Completers } \\
\hline & $\begin{array}{l}\text { Major } \\
\text { drug }^{\mathrm{a}}\end{array}$ & $\begin{array}{l}\text { Any } \\
\text { use }^{\text {b }}\end{array}$ & $\begin{array}{l}\text { Major } \\
\text { drug }\end{array}$ & $\begin{array}{l}\text { Any } \\
\text { use }\end{array}$ \\
\hline Alcohol & $0(0)$ & $5(83)$ & $0(0)$ & $17(85)$ \\
\hline Heroin & $0(0)$ & $0(0)$ & $0(0)$ & $0(0)$ \\
\hline Barbiturates & $0(0)$ & $0(0)$ & $0(0)$ & $0(0)$ \\
\hline Sedatives/Hypnotics/Tranqs & $0(0)$ & $\mid(\mid 7)$ & $0(0)$ & । (5) \\
\hline Cocaine & $0(0)$ & $2(33)$ & I (5) & $4(20)$ \\
\hline Amphetamines & $0(0)$ & $\mid(\mid 7)$ & $0(0)$ & $0(0)$ \\
\hline Methamphetamine & $6(100)$ & $6(100)$ & $18(90)$ & $20(100)$ \\
\hline Cannabis & $0(0)$ & $4(67)$ & $0(0)$ & II (55) \\
\hline Inhalants & $0(0)$ & $0(0)$ & $0(0)$ & I (5) \\
\hline Nicotine & $0(0)$ & $6(100)$ & $0(0)$ & $15(75)$ \\
\hline More than I subs/day & $0(0)$ & $4(67)$ & I (5) & $15(75)$ \\
\hline
\end{tabular}

${ }^{a}$ The number and percent of subjects for whom the drug is the major substance use problem.

${ }^{\mathrm{b}}$ The number and percent of subjects who reported any use of the substance in the last 30 days.

completers reported use of several substances, including nicotine (75\%), marijuana (55\%), and alcohol (85\%), in the past 30 days. Participants had significant past histories of abuse of other drugs, including past cocaine dependence, past alcohol abuse or dependence, and past marijuana abuse or dependence.

\section{Subjective Effects}

There were significant effects of methamphetamine on all VAS measures other than 'depression'. There were significant interactions between Bupropion ( 0 vs $150 \mathrm{mg}$ ) and Period (before $v s$ after initiation of treatment) for ratings of 'any drug effect' $(p<0.02)$, 'high' $(p<0.02)$, and there was a trend for ratings of 'stimulated' $(p<0.07)$. For 'any drug', there was a trend for a three-way interaction between Methamphetamine, Bupropion, and Period 
Table 3 Participant Demographics and Drug Use Data for Completers Only

\begin{tabular}{|c|c|c|c|c|}
\hline & $\begin{array}{c}\text { Bupropion } \\
(N=10)\end{array}$ & $\begin{array}{l}\text { Placebo } \\
(N=10)\end{array}$ & $\begin{array}{c}\text { Total } \\
(N=20)\end{array}$ & \\
\hline \multicolumn{5}{|l|}{ Gender, N (\%) } \\
\hline Male & $5(50)$ & $8(80)$ & $13(65)$ & \\
\hline Female & $5(50)$ & $2(20)$ & $7(35)$ & \\
\hline \multicolumn{5}{|l|}{ Single major race, $N(\%)$} \\
\hline White, not Hispanic & $6(60)$ & $5(50)$ & II (55) & \\
\hline Hispanic or Latino & $3(30)$ & $3(30)$ & $6(30)$ & \\
\hline African American or Black & $0(0)$ & I (10) & । (5) & \\
\hline Other & I (I0) & I (I0) & $2(10)$ & \\
\hline \multicolumn{5}{|l|}{ Age (years) } \\
\hline \multirow[t]{3}{*}{ Mean $\pm S D$} & $32 \pm 10.4$ & $33.5 \pm 6.3$ & $32.8 \pm 8.4$ & \\
\hline & \multicolumn{2}{|c|}{ Bupropion } & \multicolumn{2}{|c|}{ Placebo } \\
\hline & $\begin{array}{l}\text { Major } \\
\text { drug }^{\mathrm{a}}\end{array}$ & $\begin{array}{l}\text { Any } \\
\text { use }\end{array}$ & $\begin{array}{l}\text { Major } \\
\text { drug }\end{array}$ & $\begin{array}{l}\text { Any } \\
\text { use }\end{array}$ \\
\hline Alcohol & $0(0)$ & $8(80)$ & $0(0)$ & $9(90)$ \\
\hline Heroin & $0(0)$ & $0(0)$ & $0(0)$ & $0(0)$ \\
\hline Barbiturates & $0(0)$ & $0(0)$ & $0(0)$ & $0(0)$ \\
\hline Sedatives/Hypnotics/Tranqs & $0(0)$ & $0(0)$ & $0(0)$ & I (I0) \\
\hline Cocaine & $0(0)$ & $0(0)$ & I (10) & $4(40)$ \\
\hline Amphetamines & $0(0)$ & $0(0)$ & $0(0)$ & $0(0)$ \\
\hline Methamphetamine & $9(90)$ & $10(100)$ & $9(90)$ & $10(100)$ \\
\hline Cannabis & $0(0)$ & $5(50)$ & $0(0)$ & $6(60)$ \\
\hline Inhalants & $0(0)$ & I (I0) & $0(0)$ & $0(0)$ \\
\hline Nicotine & $0(0)$ & $8(80)$ & $0(0)$ & $7(70)$ \\
\hline More than one subs/day & I (I0) & $6(60)$ & $0(0)$ & $9(90)$ \\
\hline
\end{tabular}

${ }^{a}$ The number and percent of subjects for whom the drug is the major substance use problem.

${ }^{b}$ The number and percent of subjects who reported any use of the substance in the last 30 days.

$(p<0.08)$. This indicated that during the medication treatment phase of the study, volunteers receiving bupropion reported reduced responses on these measures compared to those receiving placebo. In addition, there was a trend for a Bupropion by Period interaction $(p<0.10)$ for 'likely to use' and 'desire'. There were significant Bupropion by Methamphetamine interactions for both 'desire' and 'likely to use' scores $(p<0.05)$. In both cases, patients receiving placebo showed higher ratings following the $30 \mathrm{mg}$ dose of MA, as compared to the $15 \mathrm{mg}$ dose. Of interest, patients receiving bupropion did not show this dose-related increase, although the effects of Period were not significant. There were no Bupropion effects on 'good effects', 'bad effects', 'liking', 'depression', or 'anxious' scores. In addition, there were no Bupropion effects on the 'pay for the drug' rating following methamphetamine administration. There was no Bupropion effect on responses on the MCQ.
The analyses were repeated using the maximum effect on each rating scale. Very similar results were obtained. Specifically, 'any drug effect' and 'high' remained significant and the three-way interaction for 'any drug effect' became significant, as did the two-way interaction (Bupropion and Period) for 'stimulated'.

For simplicity, and to highlight the most important findings, time-course data from the Treatment phase are shown for 'Any Drug' (Figure 1), 'High' (Figure 2), and 'Stimulated' (Figure 3).

\section{Craving}

Exposure to the neutral cue produced minimal, nonsignificant changes in craving ratings. Before initiation of bupropion/placebo treatment, there were no significant Bupropion by cue exposure (before/after) interaction effects. This indicated that the groups did not differ in the magnitude of cue-induced craving at before initiation of active treatment. Following initiation of bupropion/placebo treatment, there were significant Bupropion by cue exposure (before/after) interactions in GCS Total Score $(p<0.002)$ and in the Behavioral Intention subscale of the GCS $(p<0.001)$. This indicated that treatment with bupropion, compared to placebo, was associated with significantly reduced cue-induced craving (Figure 4). Similar results were obtained for WSRS 'likely to use'. There was a significant Bupropion by Period by cue exposure interaction $(p<0.02)$, indicating that during active treatment ratings on this scale were lower. There were no significant effects of bupropion treatment on the WSRS 'feel like using' scores. In general, GCS total scores and scores on each of the subscales were greater prior to randomization, and declined thereafter, possibly indicating that hospitalization, by removing participants from their usual cue-rich environments, reduced cue reactivity.

\section{ARCI, BPRS, and Adjective Scales}

Among the ARCI subscales, the pentobarbital-chlorpromazine-alcohol group (PCAG) subscale scores (reflecting sedative effects) decreased with increasing methamphet amine dose, whereas scores on the remaining subscales increased with increasing methamphetamine dose. The only significant Bupropion by Period interaction was seen for the LSD subscale, for which there was a threeway interaction between Bupropion, Period, and Methamphetamine dose $(p<0.05)$. Among the Adjective Scales, significant $(p<0.05)$ Bupropion by Period interactions were found for 'tremor', 'fidgety', and 'nervous'. Mean values for 'tremor' were low in both groups, reducing the implications of the statistical findings. For the 'fidgety' and 'nervous' ratings, bupropion reduced effects of methamphetamine on these measures during the active medication phase.

BPRS ratings were greater than mild on only 25 of approximately 3215 rating events. Ratings other than mild were more common after $30 \mathrm{mg}$ methamphetamine than after 15 or $0 \mathrm{mg}$. In all, 12 of the 25 ratings of greater than mild occurred following randomization, and there was no effect of Bupropion treatment on the BPRS ratings. 


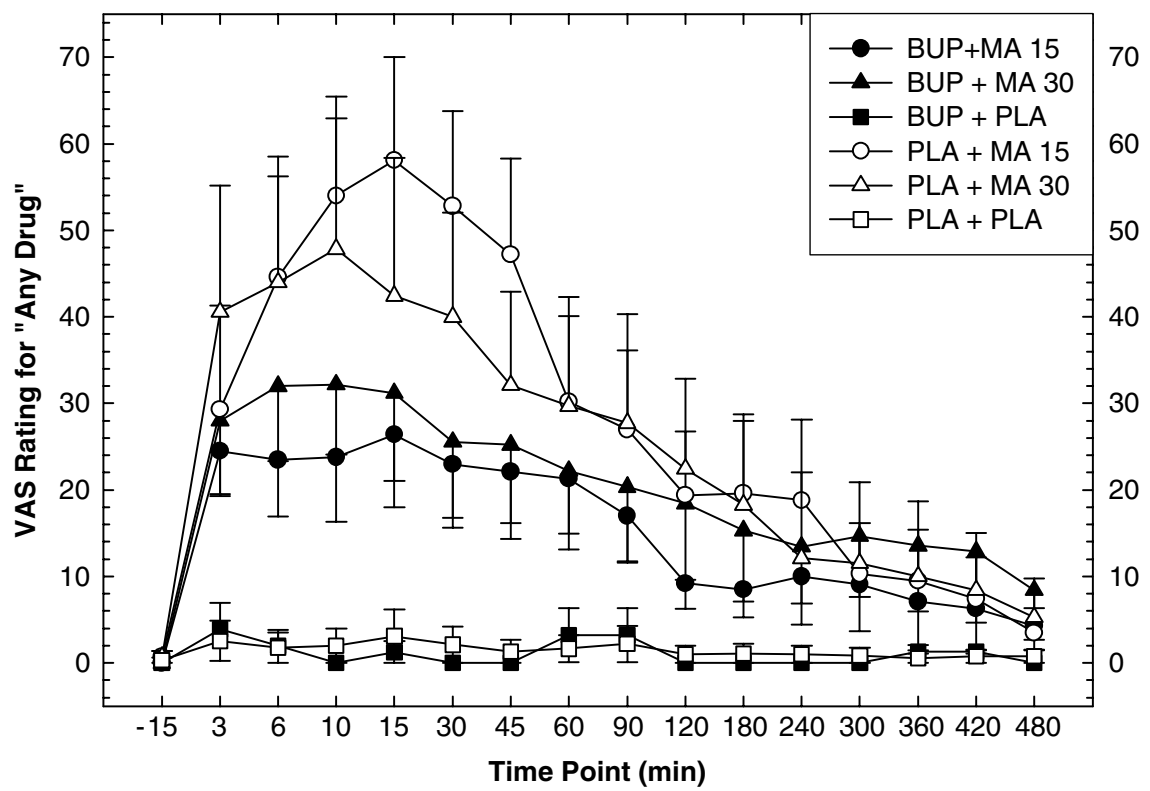

Figure I Ratings for 'any drug' Effects (mean \pm SEM). The full time-course is shown following acute administration of placebo (squares), I $5 \mathrm{mg}$ (circles), and $30 \mathrm{mg}$ (triangles) methamphetamine 6 days after initiation of twice-daily oral placebo (open symbols) or bupropion (filled symbols).

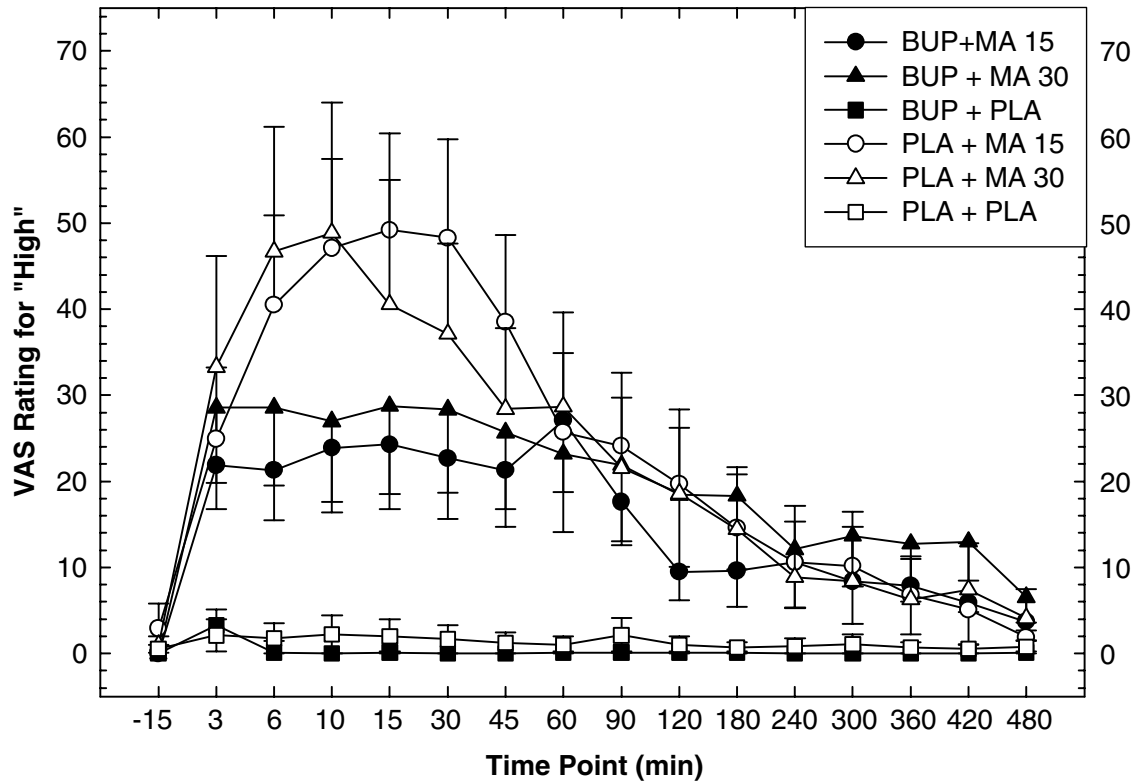

Figure 2 Ratings for 'high' (mean \pm SEM). The full time-course is shown following acute administration of placebo (squares), $15 \mathrm{mg}$ (circles), and $30 \mathrm{mg}$ (triangles) methamphetamine 6 days after initiation of twice-daily oral placebo (open symbols) or bupropion (filled symbols).

\section{DISCUSSION}

This group of methamphetamine using volunteers tolerated administration of methamphetamine during treatment with bupropion with no evidence that bupropion enhanced the effects of methamphetamine, or produced behavioral toxicity. Adverse events observed in this study were minor, with both active and placebo groups reporting similar magnitude and severity of events. In fact, bupropion treatment tended to blunt the cardiovascular effects of experimentally administered methamphetamine, with this effect reaching statistical significance for heart rate (Newton et al, 2005).
BPRS assessment was included to screen for behavioral toxicity of methamphetamine and to determine if bupropion treatment altered these responses. Very little evidence for behavioral toxicity (eg agitation or psychosis) emerged following administration of methamphetamine, and bupropion treatment did not significantly alter these responses.

Of particular interest, bupropion treatment was associated with reduced 'any drug' and 'high' ratings following methamphetamine administration. Ratings of 'high' and increased scores on ARCI subscales have been associated with abuse liability (Fischman and Foltin, 1991). Bupropion reduced several drug-related subjective effects and did not 


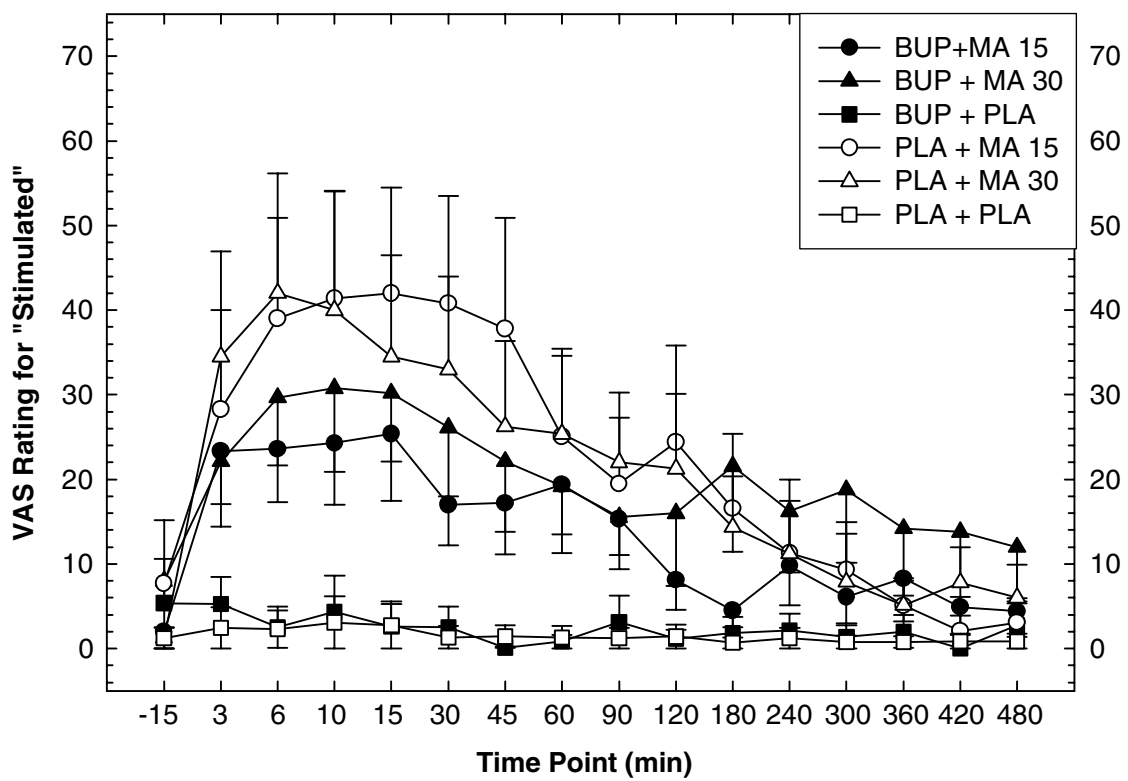

Figure 3 Ratings for 'stimulated' (mean \pm SEM). The full time-course is shown following acute administration of placebo (squares), I 5 mg (circles), and $30 \mathrm{mg}$ (triangles) methamphetamine 6 days after initiation of twice-daily oral placebo (open symbols) or bupropion (filled symbols).

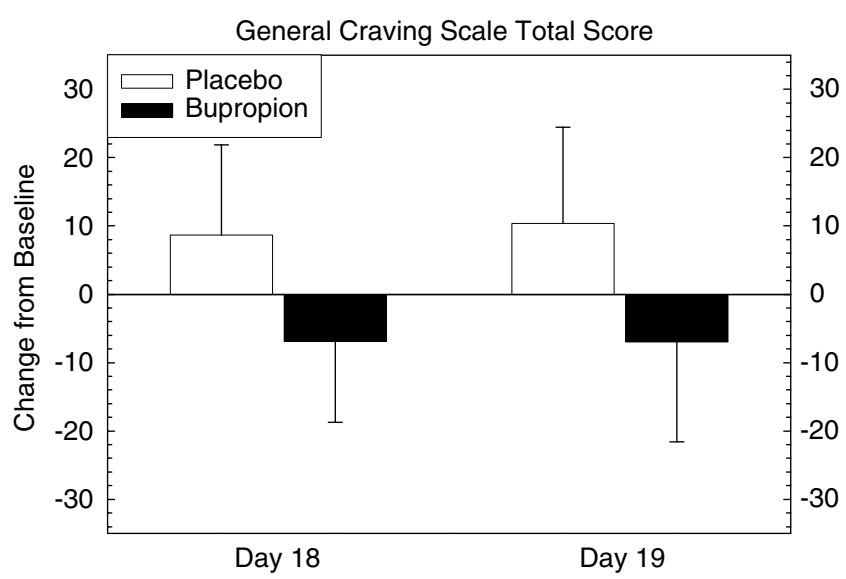

Figure 4 Effects of cue exposure on craving (mean \pm SEM). Bupropion treatment (filled bars) significantly reduced cue-induced changes in craving, as compared to effects observed in patients treated with placebo (open bars).

increase ARCI ratings, suggesting that bupropion treatment did not increase the abuse liability of methamphetamine. Instead, bupropion treatment reduced 'any drug' and 'high' ratings, suggesting that bupropion may reduce the abuse liability of methamphetamine. Confirmatory studies utilizing self-administration approaches would be useful to expand upon these findings. The impact of bupropion treatment on methamphetamine use outside of the laboratory (where much larger doses are used) can only be assessed in an outpatient clinical trial.

Bupropion treatment was associated with reduced cueinduced craving. The GCS was modeled on craving scales developed for craving for cocaine and smoking urges (Merikle, 1999; Tiffany and Drobes, 1991; Tiffany et al, 1993). Thus, the GCS captures more dimensions of craving than do visual analogue scales (Tiffany et al, 1993). In drug discrimination tests in pigeons and rats, bupropion substitutes for methamphetamine (Johanson and Barrett, 1993; Munzar and Goldberg, 2000; Sasaki et al, 1995). In addition, bupropion is self-administered intravenously (i.v.) by squirrel monkeys and baboons (Bergman et al, 1989; Lamb and Griffiths, 1990), indicating that i.v. bupropion produces reinforcing effects in non-human primates similar to that produced by commonly abused stimulants (cocaine, methamphetamine). Differences between the drugs emerge when bupropion and methamphetamine are administered together. Bupropion pretreatment antagonizes methamphetamine-induced stereotypy, but when administered following methamphetamine, bupropion treatment augments methamphetamine-induced stereotypy (Muley et al, 1984).

These disparate results can be explained by the known effects of bupropion on the DA transporter (DAT). In an in vitro model consisting of immortalized cells transfected with the human DAT, bupropion dose dependently inhibited DA reuptake (Eshleman et al, 1994). On the other hand, bupropion pretreatment has been shown to protect against acute methamphetamine-induced decreases in DA uptake in striatal synaptasomes (Kim et al, 2000). Similar effects have been reported in vivo, as bupropion pretreatment reduced the neurotoxic effects produced by a single large dose $(100 \mathrm{mg} / \mathrm{kg}$, s.c. $)$ of methamphetamine in rats (Marek et al, 1990). These effects appear to be due to the ability of bupropion to inhibit the inward transport of methamphetamine, thus limiting the ability of methamphetamine to displace DA from vesicular stores. In a recent report (Rau et al, 2005), bupropion rapidly, reversibly, and dose dependently increased vesicular DA uptake, an effect associated with vesicular monoamine transporter-2 protein redistribution. Of interest, the bupropion-induced increases in vesicular DA uptake were prevented by pretreatment with eticlopride, a $\mathrm{DA} \mathrm{D}_{2}$ receptor antagonist, but not by $\mathrm{SCH}$ 23390 , a $\mathrm{DA} \mathrm{D}_{1}$ receptor antagonist. 
When administered alone, bupropion increases synaptic DA by inhibiting reuptake. When administered with methamphetamine, bupropion may reduce synaptic DA by reducing the ability of methamphetamine to induce DA release. Bupropion has been reported to produce agonistlike effects in acutely abstinent smokers (Shiffman et al, 2000). As such, reduced ratings on subjective effects measures in this study may have been the result of the ability of bupropion to inhibit methamphetamine-induced DA release.

Despite this information, DA may not be the sole neurotransmitter system mediating the effects produced by bupropion. For example, bupropion does not inhibit prolactin, which would be expected if it significantly increases central DA (Whiteman et al, 1983). Moreover, therapeutic doses of bupropion have been reported to produce just $25 \%$ occupancy of the DA transporter (Learned-Coughlin et al, 2003), which may be inadequate to account for alterations to methamphetamine-induced DA release (Dworkin et al, 1998). Finally, other data suggest that stimulants (including methamphetamine) release norepinepherine (NE) more potently than DA (Rothman et al, 2001), and this neurotransmitter system may be responsible for some of the subjective effects reported in the current study.

We also found that bupropion blocked cue-induced craving. Similar results were reported in smokers, as bupropion treatment was associated with reduced cigarette cue-induced craving (Brody et al, 2004). The observed effects may have been the result of inhibition of $\mathrm{NE}$ reuptake, resulting in increased extracellular NE, which in turn reduced NE cell firing (Dong and Blier, 2001). Reduced NE output would, in turn, produce reduced cue reactivity and associated changes in cerebral metabolic activity.

The findings in this report are subject to a range of limitations. While bupropion pretreatment reliably reduced some of the subjective effects produced by methamphetamine, the doses of methamphetamine used were small. Methamphetamine-addicted individuals typically use much greater amounts, and may be prone to overcome modest reductions produced by a given medication (eg bupropion). In fact, preclinical models of self-administration demonstrate that reductions in subjective or reinforcing effects are generally accompanied by an increase in the amount of drug administered. Of interest, group differences were not noted between the 15 and $30 \mathrm{mg}$ doses of methamphetamine. A careful analysis of individual responses revealed that this was likely the result of the considerable variability between subjects. Specifically, some patients exhibited moderate to robust responses to methamphetamine exposure, while others show little or no response. When considering only the group means, the impression is that the doses produced equivalent effects (which underestimates the individual responses to the drug). An additional limitation of the current study is the use of low doses of methamaphetamine and an equally low dose of bupropion. The doses selected were chosen on the basis of safety information showing that higher doses of bupropion are associated with onset of seizures (Pesola and Avasarala, 2002). In addition, the Physicians Desk Reference website (www.pdr.net) specifies, 'Zyban is contraindicated in patients with a seizure disorder, Zyban is contraindicated in patients treated with
Wellbutrin, Wellbutrin SR, Wellbutrin XL, or any other medications that contain bupropion because the incidence of seizure is dose dependent, and Zyban is contraindicated in patients with a current or prior diagnosis of bulimia or anorexia nervosa because of a higher incidence of seizures noted in patients treated for bulimia with the immediaterelease formulation of bupropion'. Moreover, the PDR site specifies caution for the interactions of bupropion with stimulants. Specifically, 'Circumstances associated with an increased seizure risk include, among others, excessive use of alcohol or sedatives (including benzodiazepines); addiction to opiates, cocaine, or stimulants; use of over-thecounter stimulants and anorectics; and diabetes treated with oral hypoglycemics or insulin'. A final limitation worth noting is the short exposure regimen and small sample size, signaling the need to replicate and extend these findings in a larger cohort (ie in a Phase II clinical trial).

The finding that bupropion reduced cue-induced craving for methamphetamine is especially compelling, although in the absence of other measures of drug seeking behavior (such as self-administration) it is difficult to infer the consequences of reduced craving. Furthermore, based on research with cue exposure in cocaine users (Robbins et al, 1997), it is likely that not all methamphetamine users respond to cues with increased craving. Further research in more homogenous populations may facilitate identification of subgroups that would best respond to treatments that alter cue responsivity.

\section{ACKNOWLEDGEMENTS}

This project was supported by contracts from NIDA (DA-08804, DA 014593 and RR-00865).

\section{REFERENCES}

Bergman J, Madras BK, Johnson SE, Spealman RD (1989). Effects of cocaine and related drugs in nonhuman primates. III. Selfadministration by squirrel monkeys. J Pharmacol Exp Ther 251: 150-155.

Brody AL, Mandelkern MA, Lee G, Smith E, Sadeghi M, Saxena S et al (2004). Attenuation of cue-induced cigarette craving and anterior cingulate cortex activation in bupropion-treated smokers: a preliminary study. Psychiatry Res: Neuroimaging 130: $269-281$.

de Lima MS, de Oliveira Soares BG, Reisser AA, Farrell M (2002). Pharmacological treatment of cocaine dependence: a systematic review. Addiction 97: 931-949.

Dong J, Blier P (2001). Modification of norepinephrine and serotonin, but not dopamine, neuron firing by sustained bupropion treatment. Psychopharmacology (Berl) 155: 52-57.

Dworkin SI, Lambert P, Sizemore GM, Carroll FI, Kuhar MJ (1998). RTI-113 administration reduces cocaine self-administration at high occupancy of dopamine transporter. Synapse 30: 49-55.

Ehrman RN, Robbins SJ, Childress AR, O'Brien CP (1992). Conditioned responses to cocaine-related stimuli in cocaine abuse patients. Psychopharmacology 107: 523-529.

Eshleman AJ, Henningsen RA, Neve KA, Janowsky A (1994). Release of dopamine via the human transporter. Mol Pharmacol 45: 312-316.

Fischman MW, Foltin RW (1991). Utility of subjective-effects measurements in assessing abuse liability of drugs in humans. $\mathrm{Br}$ J Addict 86: 1563-1570. 
Galloway GP, Newmeyer J, Knapp T, Stalcup SA, Smith D (1994). Imipramine for the treatment of cocaine and methamphetamine dependence. J Addict Dis 13: 201-216.

Galloway GP, Newmeyer J, Knapp T, Stalcup SA, Smith D (1996). A controlled trial of imipramine for the treatment of methamphetamine dependence. J Subst Abuse Treat 13: 493-497.

Garbutt JC, West SL, Carey TS, Lohr KN, Crews FT (1999). Pharmacological treatment of alcohol dependence: a review of the evidence [see comments]. JAMA 281: 1318-1325.

Haertzen CA (1965). Addiction Research Center Inventory (ARCI): development of a general drug estimation scale. J Nerv Ment Dis 141: 300-307.

Haertzen CA (1966). Development of scales based on patterns of drug effects, using the addiction Research Center Inventory (ARCI). Psychol Rep 18: 163-194.

Huber A, Ling W, Shoptaw S, Gulati V, Brethen P, Rawson R (1997). Integrating treatments for methamphetamine abuse: a psychosocial perspective. J Addict Dis 16: 41-50.

Huber A, Shoptaw S, Gulati VRG (2000). Sertraline and contingency management as treatments for methamphetamine dependence. Data presented at the annual meeting of the College on the Problems of Drug Dependence, San Juan, PR. pp 70.

Johanson CE, Barrett JE (1993). The discriminative stimulus effects of cocaine in pigeons. J Pharmacol Exp Ther 267: 1-8.

Kim S, Westphalen R, Callahan B, Hatzidimitriou G, Yuan J, Ricaurte GA (2000). Toward development of an in vitro model of methamphetamine-induced dopamine nerve terminal toxicity. J Pharmacol Exp Ther 293: 625-633.

Lamb RJ, Griffiths RR (1990). Self-administration in baboons and the discriminative stimulus effects in rats of bupropion, nomifensine, diclofensine and imipramine. Psychopharmacology (Berl) 102: 183-190.

Learned-Coughlin SM, Bergstrom M, Savitcheva I, Ascher J, Schmith VD, Langstrom B (2003). In vivo activity of bupropion at the human dopamine transporter as measured by positron emission tomography. Biol Psychiatry 54: 800-805.

Marek GJ, Vosmer G, Seiden LS (1990). Dopamine uptake inhibitors block long-term neurotoxic effects of methamphetamine upon dopaminergic neurons. Brain Res 513: 274-279.

Margolin A, Kosten TR, Avants SK, Wilkins J, Ling W, Beckson M et al (1995). A multicenter trial of bupropion for cocaine dependence in methadone-maintained patients. Drug Alcohol Depend 40: 125-131.

Mattick RP, Kimber J, Breen C, Davoli M (2002). Buprenorphine maintenance versus placebo or methadone maintenance for opioid dependence. Cochrane Database Syst Rev CD002207.

McCann UD, Wong DF, Yokoi F, Villemagne V, Dannals RF, Ricaurte GA (1998). Reduced striatal dopamine transporter density in abstinent methamphetamine and methcathinone users: evidence from positron emission tomography studies with [11C]WIN-35,428. J Neurosci 18: 8417-8422.

Merikle EP (1999). The subjective experience of craving: an exploratory analysis. Subst Use Misuse 34: 1101-1115.

Muley MP, Joshi MA, Manekar MS (1984). Effect of bupropion on dopamine and 5-hydroxytryptamine-mediated behaviour in mice. J Pharm Pharmacol 36: 208-210.

Munzar P, Goldberg SR (2000). Dopaminergic involvement in the discriminative-stimulus effects of methamphetamine in rats. Psychopharmacology (Berl) 148: 209-216.

Newton TF, Kalechstein AD, Duran S, Vansluis N, Ling W (2004). Methamphetamine abstinence syndrome: preliminary findings. Am J Addict 13: 248-255.

Newton TF, Roache JD, De La Garza II R, Fong T, Wallace CL, Li SH et al (2005). Safety of intravenous methamphetamine administration during treatment with bupropion. Psychopharmacology 182: 426-435.
O’Brien CP, Testa T, O’Brien TJ, Greenstein R (1976). Conditioning in human opiate addicts. Pavlov J Biol Sci 11: 195-202.

Overall JE, Gorham DR (1962). The Brief Psychiatric Rating Scale. Psychol Rep 10: 799-812.

Pesola GR, Avasarala J (2002). Bupropion seizure proportion among new-onset generalized seizures and drug related seizures presenting to an emergency department. J Emerg Med 22: 235-239.

Rau KS, Birdsall E, Hanson JE, Johnson-Davis KL, Carroll FI, Wilkins DG et al (2005). Bupropion increases striatal vesicular monoamine transport. Neuropharmacology 49: 820-830.

Rawson R, McCann M, Huber A, Shoptaw S (1999). Contingency management and relapse prevention as stimulant abuse treatment interventions motivating behavior change among illicit-drug abusers: research on contingency management interventions. American Psychological Association, Washington, DC, US. pp 57-74.

Rawson RA, Marinelli-Casey P, Anglin MD, Dickow A, Frazier Y, Gallagher C et al (2004). A multi-site comparison of psychosocial approaches for the treatment of methamphetamine dependence. Addiction 99: 708-717.

Richmond R, Zwar N (2003). Review of bupropion for smoking cessation. Drug Alcohol Rev 22: 203-220.

Robbins SJ, Ehrman RN, Childress AR, O’Brien CP (1997). Relationships among physiological and self-report responses produced by cocaine-related cues. Addict Behav 22: 157-167.

Rothman RB, Baumann MH, Dersch CM, Romero DV, Rice KC, Carroll FI et al (2001). Amphetamine-type central nervous system stimulants release norepinephrine more potently than they release dopamine and serotonin. Synapse 39: 32-41.

Sasaki JE, Tatham TA, Barrett JE (1995). The discriminative stimulus effects of methamphetamine in pigeons. Psychopharmacology (Berl) 120: 303-310.

Sekine Y, Minabe Y, Ouchi Y, Takei N, Iyo M, Nakamura K et al (2003). Association of dopamine transporter loss in the orbitofrontal and dorsolateral prefrontal cortices with methamphetamine-related psychiatric symptoms. Am J Psychiatry 160: 1699-1701.

Shiffman S, Johnston JA, Khayrallah M, Elash CA, Gwaltney CJ, Paty JA et al (2000). The effect of bupropion on nicotine craving and withdrawal. Psychopharmacology (Berl) 148: 33-40.

Shoptaw S, Rawson RA, McCann MJ, Obert JL (1994). The Matrix model of outpatient stimulant abuse treatment: evidence of efficacy. J Addict Dis 13: 129-141.

Sofuoglu M, Kosten TR (2005). Novel approaches to the treatment of cocaine addiction. CNS Drugs 19: 13-25.

Stahl SM, Pradko JF, Haight BR, Modell JG, Rockett CB, LearnedCoughlin S (2004). A review of the neuropharmacology of bupropion, a dual norepinephrine and dopamine reuptake inhibitor. Prim Care Companion J Clin Psychiatry 6: 159-166.

Tiffany ST, Drobes DJ (1991). The development and initial validation of a questionnaire on smoking urges. $\mathrm{Br} J$ Addict 86: 1467-1476.

Tiffany ST, Singleton E, Haertzen CA, Henningfield JE (1993). The development of a cocaine craving questionnaire. Drug Alcohol Depend 34: 19-28.

Volkow ND, Chang L, Wang GJ, Fowler JS, Franceschi D, Sedler M et al (2001). Loss of dopamine transporters in methamphetamine abusers recovers with protracted abstinence. J Neurosci 21: 9414-9418.

Whiteman PD, Peck AW, Fowle AS, Smith PR (1983). Failure of bupropion to affect prolactin or growth hormone in man. J Clin Psychiatry 44: 209-210.

Wilson JM, Kalasinsky KS, Levey AI, Bergeron C, Reiber G, Anthony RM et al (1996). Striatal dopamine nerve terminal markers in human, chronic methamphetamine users. Nat Med 2: 699-703. 